\title{
Integrated care in action: A practical guide for health, social care and housing support
}

\author{
Robin Miller, Hilary Brown and Catherine Mangan (Eds.), 2016 \\ Jessica Kingsley Publishers, UK \\ ISBN 978-1-84905-646-5, pp. 232, paperback, AUD51.25
}

$I$ ntegrated Care in Action provides a practical and engaging narrative for managers already working within, or working towards, integrated service delivery, as well as for students and others eager to better understand possible designs, models and tools with which to achieve integration goals.

The authors offer the view that "integration is concerned with a fluid set of interactions between individuals accessing services ... professionals who support them, and organisations and policy contexts" and set about providing tools to support those interactions and the actors at large (p. 8). This theme is woven throughout the various chapters based upon the building blocks which, the authors argue, are integral in the success of an integrated care initiative.

The style of the chapters encourages the reader to dip in and out of the chapters that appear most relevant, while also providing a powerful continuum when read in the order the chapters are displayed.

For those looking for practical tools, programmes or models there are also plenty of these on offer. Easily recognisable tools such as the PDSA (Plan Do Study Act) cycles sit comfortably alongside Kotter's 8-Step Change Model and co-production frameworks such as Experience Based Design. Working with and leading staff feature largely, with good resources to empower and manage resilience throughout the possible paths to integration.

For those seeking to undertake change processes, this text provides a framework for readers to understand the types of change in order to engage with it. This focus creates a space for the reader to reflect on the tools provided throughout the book.

So, too, do the variety of real-life case examples which demonstrate the application of concepts and tools described in each chapter. While many of the case examples provided are from the UK and NHS perspective, they are framed in a way so as to be meaningful to an international audience.

Overall, Dr Robin Miller, Hilary Brown and Catherine Mangan have produced an easily readable, engaging text which feels immediately useful and realistic for any health and social care setting. They invite the reader to think about their own current state and, through well placed questions, invite the reader to imagine an integrated future.

As the authors highlight, "this is a start, and not the finish" (p. 114). They encourage us as readers to look more deeply into the areas that capture our attention and the tools that could be useful within our own actions towards Integrated Care. They also remind us that "Integrated care is ... a long term endeavour ... which will always require our attention and energies" (p. 210). 